Research article

Open Access

\title{
Expression profiling of metalloproteinases and their inhibitors in synovium and cartilage
}

\author{
Rose K Davidson ${ }^{1}$, Jasmine G Waters ${ }^{1}$, Lara Kevorkian¹, Clare Darrah², Adele Cooper², \\ Simon T Donell ${ }^{2}$ and lan M Clark ${ }^{1}$
}

\author{
${ }^{1}$ School of Biological Sciences, University of East Anglia, Norwich NR4 7TJ, UK \\ 2Institute of Orthopaedics, Norfolk and Norwich University Hospital, Norwich NR4 7UY, UK \\ Corresponding author: lan M Clark, i.clark@uea.ac.uk \\ Received: 24 May 2006 Revisions requested: 19 Jun 2006 Revisions received: 11 Jul 2006 Accepted: 14 Jul 2006 Published: 19 Jul 2006 \\ Arthritis Research \& Therapy 2006, 8:R124 (doi:10.1186/ar2013) \\ This article is online at: http://arthritis-research.com/content/8/4/R124 \\ (C) 2006 Davidson et al.; licensee BioMed Central Ltd. \\ This is an open access article distributed under the terms of the Creative Commons Attribution License (http://creativecommons.org/licenses/by/2.0), \\ which permits unrestricted use, distribution, and reproduction in any medium, provided the original work is properly cited.
}

\begin{abstract}
Cartilage destruction in osteoarthritis $(\mathrm{OA})$ is thought to be mediated by two main enzyme families; the matrix metalloproteinases (MMPs) are responsible for cartilage collagen breakdown, whereas enzymes from the 'a disintegrin and metalloproteinase domain with thrombospondin motifs' (ADAMTS) family mediate cartilage aggrecan loss. Tissue inhibitors of metalloproteinases (TIMPs) regulate the activity of these enzymes. Although cartilage destruction in OA might be driven by the chondrocyte, low-grade synovitis is reported in patients with all grades of this disease.

Our earlier work profiling these gene families in cartilage identified a number of genes that are regulated in $\mathrm{OA}$, which are hence implicated in the disease process. Because the synovium might contribute to cartilage-matrix destruction in $\mathrm{OA}$, we have extended the screening in the current study. We have profiled $M M P, A D A M T S$ and TIMP genes in both cartilage and synovium from patients with either OA of the hip or a fracture to the neck of femur (NOF), giving a more complete picture of proteolysis in this disease.
\end{abstract}

The four most significantly upregulated genes $(P<0.0001)$ in OA synovium compared to the fractured NOF are MMP28, ADAMTS16, ADAMTS17 and TIMP2. For MMP9, MMP10, MMP12, MMP17, MMP23, MMP28, ADAMTS4, and ADAMTS9, there is a significant correlation between expression levels in the synovium and cartilage, suggesting similar mechanisms of regulation. Additionally, we have shown that in cartilage the median level of steady-state mRNA for MMP13 is approximately 20-fold higher than MMP28 and approximately 1,500-fold higher than ADAMTS16, with expression of this latter gene approximately 150 -fold higher in synovium than cartilage.

This study is the most comprehensive analysis of the metzincin family of proteinases in the joint to date and has identified several proteinase genes not previously reported to be expressed or regulated in synovium.

\section{Introduction}

Osteoarthritis $(\mathrm{OA})$ is a debilitating degenerative joint disease characterized by degradation of articular cartilage. Recent statistics show that approximately 5 million people in the UK suffer from moderate-to-severe OA. These patients are predominantly older than 45 years of age, with the major morbidity in patients over 60 years of age [1]. Given the current demographic trend towards an older population, OA, for which age is an important risk factor, will be an increasing health and economic burden on society.

The molecular mechanisms underlying cartilage destruction in OA are poorly understood (reviewed in [2]). Cartilage is made up of two main extracellular matrix (ECM) macromolecules: type II collagen and aggrecan, a large aggregating proteoglycan $[3,4]$. The former endows the cartilage with its tensile strength, whereas the latter enables cartilage to resist com-

ADAMTS $=$ a disintegrin and metalloproteinase domain with thrombospondin motifs; $B L A S T=$ basic local alignment search tool; $\mathrm{C}_{\mathrm{T}}=$ threshold cycle; $\mathrm{ECM}=$ extracellular matrix; $\mathrm{K}_{\mathrm{i}}=$ inhibition constant; $\mathrm{MMP}=$ matrix metalloproteinase; $\mathrm{MRI}=$ magnetic resonance imaging; $\mathrm{NOF}=$ neck of femur; $\mathrm{OA}$ $=$ osteoarthritis; PBS = phosphate-buffered saline; PCR = polymerase chain reaction; RA = rheumatoid arthritis; TIMP = tissue inhibitor of metalloproteinases. 
pression. Quantitatively, more minor components (e.g. type IX, $\mathrm{XI}$ and $\mathrm{VI}$ collagens, biglycan, decorin and cartilage oligomeric matrix protein) also have important roles in controlling the supramolecular organization of the matrix [3]. Normal cartilage ECM is in a state of dynamic equilibrium, with a balance between synthesis and degradation. For the degradative process, there is a balance between proteinases that degrade the ECM and their inhibitors. In OA, the dogma is that a disruption of this balance, in favour of proteolysis, leads to pathological cartilage destruction.

The matrix metalloproteinases (MMPs) are a family of 23 enzymes in humans that facilitate ECM turnover and breakdown in physiology and pathology [5]. The MMP family contains the only mammalian proteinases that can specifically degrade triple helical collagens at neutral $\mathrm{pH}$. These so-called 'collagenases' specifically cleave a single locus in all three collagen chains at a point three-quarters of the length from the $\mathrm{N}$ terminus of the molecule. The 'classical' collagenases (MMP1, MMP-8 and MMP-13) have differing substrate specificities for collagens I, II and III, with MMP-13 showing a preference for type II collagen [6]. More recently, gelatinase A (MMP-2) and MT1-MMP (MMP-14) have also been shown to make the specific collagen cleavage, although with less catalytic efficiency than the classical collagenases, at least in vitro $[7,8]$. A second group of proteinases has been identified that affect ECM synthesis and degradation. The 'a disintegrin and metalloproteinase domain with thrombospondin motifs' (ADAMTS) family contains 19 members [9]; these include enzymes involved in collagen biosynthesis as procollagen propeptidases (ADAMTS-2, ADAMTS-3 and ADAMTS-14) [10-13]. Other members of the family are so-called 'aggrecanases' (ADAMTS-1, ADAMTS-4, ADAMTS-5, ADAMTS-8, ADAMTS9 and ADAMTS-15) that degrade the interglobular domain separating $\mathrm{G} 1$ and $\mathrm{G} 2$ of aggrecan at a specific Glu373Ala374 bond [14-18].

A family of four specific inhibitors, the tissue inhibitors of metalloproteinases (TIMPs), has been described [19]. These are endogenous inhibitors of MMPs and potentially the ADAMTS family. The ability of the TIMPs to block active MMPs is largely promiscuous. TIMP-3 seems to be the most potent inhibitor of the ADAMTS family, with a subnanomolar $\mathrm{K}_{\mathrm{i}}$ against ADAMTS4 and ADAMTS-5 [20].

Although the dogma has been that OA is a 'noninflammatory' disease driven by the chondrocyte, there is certainly evidence for synovial involvement. Low-grade synovitis with thickening of the lining layer, increased vascularity and inflammatory-cell infiltration is reported in patients with all grades of OA [21]. This results in the expression of cytokines and proteinases that could contribute to the pathogenesis of the disease [22]. Arthroscopic studies have also shown that inflammatory changes in the OA synovium often occur where this tissue is in contact with cartilage $[23,24]$. More recent studies using magnetic resonance imaging (MRI) reinforce the idea that synovitis is a frequent feature, even of early OA [25].

We recently published a complete expression profile of all MMPs, the ADAMTS family and the four TIMPs in normal cartilage compared with OA cartilage [26]. This identified a number of genes that are regulated in OA, which are hence implicated in the disease process. Because the synovium might contribute to cartilage-matrix destruction in OA, we have extended the screening in the current study. Hence, we have profiled MMP, ADAMTS and TIMP genes in both cartilage and synovium from normal and $O A$ joints, giving a more complete picture of proteolysis in this disease.

\section{Materials and methods Cartilage samples}

Human articular cartilage was obtained from femoral heads of patients undergoing total-hip-replacement surgery at the Norfolk and Norwich University Hospital (Norwich, UK). Samples from patients with OA ( $n=16$, of which 7 patients were female and 9 patients were male; age range, 61-84 years) were compared with cartilage from patients undergoing hip replacement following fracture to the neck of femur (NOF; $n=24$, of which 19 patients were female and 5 patients were male; age range, 52-92 years). OA was diagnosed using the clinical history and an examination, coupled with $\mathrm{X}$-ray findings; confirmation of gross pathology was made at time of joint removal. The fracture patients had no known history of joint disease and their cartilage was free of lesions; $80 \%$ of these patients underwent surgery within 36 hours of fracture. This study was performed with Ethical Committee approval and all patients provided informed consent.

\section{Femoral head dissection}

Intact femoral heads were washed in sterile PBS. Cartilage samples were removed from the femoral head using a razor blade, chopped into 2-5 $\mathrm{mm}$ pieces and snap frozen in liquid nitrogen within 15-30 minutes of surgery. Synovium was washed in sterile PBS, snap frozen and stored in liquid nitrogen.

\section{RNA extraction from articular cartilage}

Extractions were performed on the same day or within 24 hours of dissection from the femoral head following the basic method of Price et al. [27]. Cartilage was weighed and ground under liquid nitrogen using a freezer mill (SPEX CertiPrep 6750, Glen Creston, Stanmore, Middlesex, UK). TRIzol ${ }^{\circledR}$ reagent (Invitrogen, Paisley, UK) was added immediately to ground cartilage ( $1 \mathrm{ml} / 0.2 \mathrm{~g}$ cartilage); the solution was mixed thoroughly and incubated at room temperature for 5 minutes. Ground cartilage was pelleted at $9,500 \mathrm{~g}$ for 10 minutes at $4^{\circ} \mathrm{C}$ and the supernatant recovered. To each $0.5 \mathrm{ml}$ of TRIzol ${ }^{\circledR}$, $300 \mu \mathrm{l}$ of chloroform was added; the resulting solution was vortexed for 15 seconds and incubated at room temperature 10 minutes. The TRIzol ${ }^{\circledR} /$ chloroform solution was centrifuged 

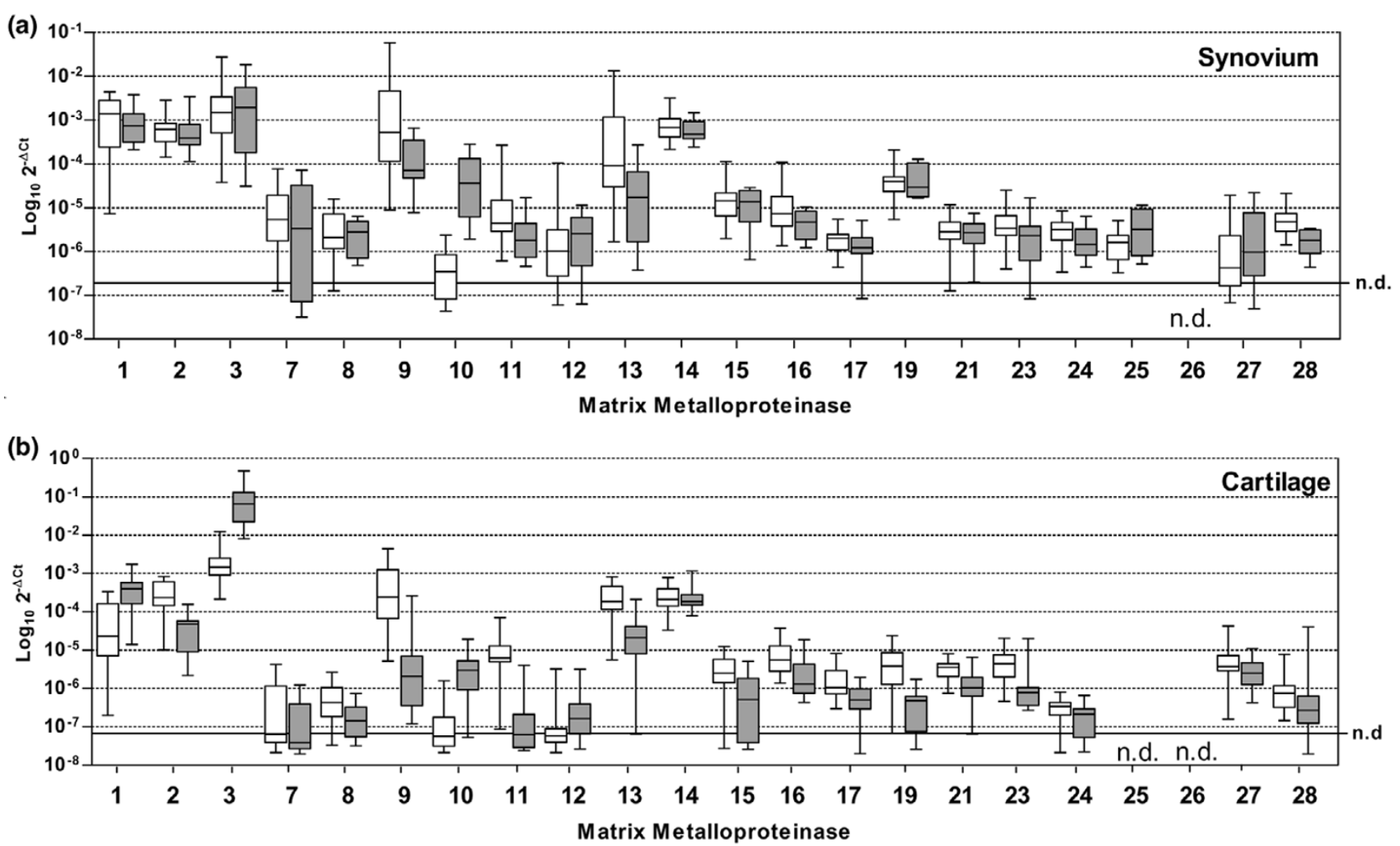

Comparative expression of MMP genes in the fractured NOF (filled boxes) compared with OA (open boxes) in hip (a) synovium and (b) cartilage. The expression level of each gene was determined, as described in Materials and methods, and normalized to the level of 185 rRNA gene expression using $\Delta \mathrm{C}_{\mathrm{T}}\left[\mathrm{C}_{\mathrm{T}}\right.$ (target gene) $\left.-\mathrm{C}_{\mathrm{T}}(18 \mathrm{~S})\right]$. The box-and-whisker plot shows median values, and each section represents a quartile of the data. Samples on or below the dotted line have $\mathrm{C}_{\mathrm{T}}$ (target gene) $=40$ and are therefore not detectable (n.d.).

at $9,500 \mathrm{~g}$ for 15 minutes at $4^{\circ} \mathrm{C}$. The aqueous layer was recovered into a fresh tube and mixed with a half volume of $100 \%$ ethanol. Using the RNeasy Mini Kit (Qiagen, Crawley, West Sussex, UK) samples were applied to spin columns and centrifuged at $9,500 \mathrm{~g}$ for 15 seconds at room temperature and the flow-through discarded. Columns were then washed and eluted according to the manufacturer's instructions. RNA samples were quantified using the NanoDrop ${ }^{\circledR}$ spectrophotometer (NanoDrop Technologies, Wilmington, Delaware, USA) and stored at $-80^{\circ} \mathrm{C}$.

\section{RNA extraction from synovium}

To each $100 \mathrm{mg}$ tissue sample, $1 \mathrm{ml}$ of TRIzol ${ }^{\circledR}$ was added; the solution was homogenized using a TissueLyser (Qiagen, Crawley, West Sussex, UK). The homogenized sample was pelleted at $9,500 \mathrm{~g}$ for 10 minutes at $4^{\circ} \mathrm{C}$ and the supernatant recovered. To each $1 \mathrm{ml}$ of TRIzol ${ }^{\circledR}, 400 \mu \mathrm{l}$ of chloroform was added; the resulting solution was vortexed for 15 seconds and incubated at room temperature for 5 minutes. Samples were centrifuged at $9,500 \mathrm{~g}$ for 10 minutes at $4^{\circ} \mathrm{C}$. The aqueous phase was recovered and $250 \mu \mathrm{l}$ of isopropanol was added. This was vortexed, as before, and incubated at room temperature for 10 minutes. The mixture was centrifuged at $9,500 \mathrm{~g}$ for
10 minutes at $4^{\circ} \mathrm{C}$ and the supernatant discarded. The RNA pellet was washed with $75 \%$ ethanol solution and centrifuged at $9,500 \mathrm{~g}$ for 5 minutes at $4^{\circ} \mathrm{C}$. The supernatant was discarded, and the pellet was air dried and then suspended in 20 $\mu$ of RNAse-free water. The RNA was incubated at $55^{\circ} \mathrm{C}$ for 10 minutes before storage at $-80^{\circ} \mathrm{C}$. RNA samples were quantified using the NanoDrop ${ }^{\circledR}$ spectrophotometer (NanoDrop Technologies, Wilmington, Delaware, USA).

\section{Synthesis of cDNA}

cDNA was synthesised from $1 \mu \mathrm{g}$ of total RNA using Superscript II reverse transcriptase (Invitrogen, Paisley, UK) and random hexamers in a total volume of $20 \mu \mathrm{l}$ according to the manufacturer's instructions. cDNA was stored at $-20^{\circ} \mathrm{C}$ until used in downstream PCR.

\section{Quantitative real-time PCR}

Oligonucleotide primers and fluorescent-labelled probes were designed using Primer Express 1.0 software (Applied Biosystems, Warrington, UK). Sequences for MMP and TIMP primers and probes are as described in [28] and sequences for ADAMTS primers and probes are as described in [29]. To control against amplification of genomic DNA, primers were 
Figure 2
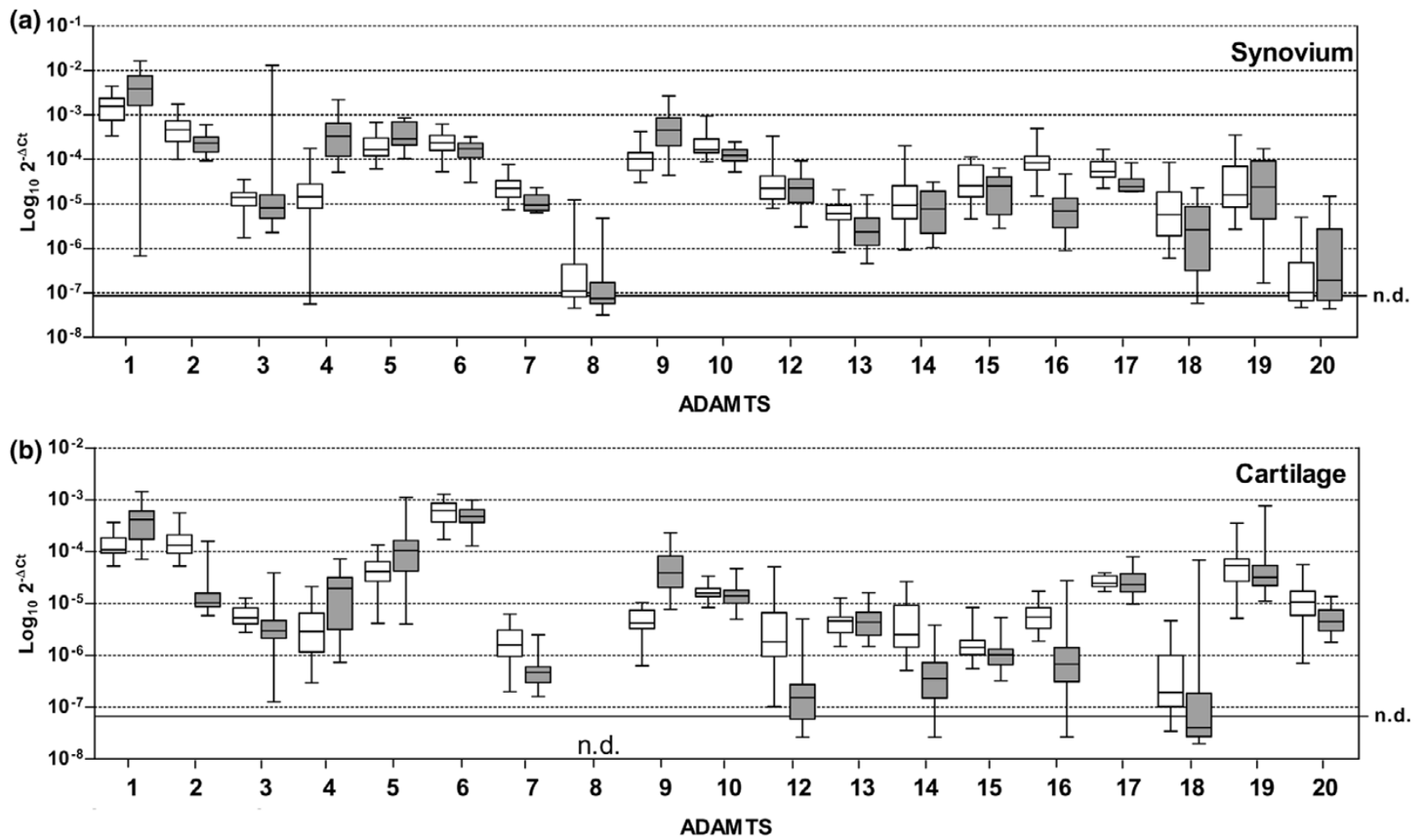

Comparative expression of ADAMTS genes in the fractured NOF (filled boxes) compared with OA (open boxes) hip (a) synovium and (b) cartilage. The expression level of each gene was determined, as described in Materials and methods, and normalized to the level of 18S rRNA gene expression using $\Delta \mathrm{C}_{\mathrm{T}}\left[\mathrm{C}_{\mathrm{T}}\right.$ (target gene) $\left.-\mathrm{C}_{\mathrm{T}}(18 \mathrm{~S})\right]$. The box-and-whisker plot shows median values, and each section represents a quartile of the data. Samples on or below the dotted line have $\mathrm{C}_{\mathrm{T}}$ (target gene) $=40$ and are therefore not detectable (n.d.).

placed within different exons close to an intron/exon boundary, with the probe spanning two neighbouring exons where possible. The BLAST was used to search for all the primer and probe sequences to ensure gene specificity. The $18 \mathrm{~S}$ rRNA gene was used as an endogenous control to normalize for differences in the amount of total RNA present in each sample; the 18S rRNA primers and probe were purchased from Applied Biosystems (Warrington, UK). Primers for detection of specific splice variants of MMP28 were as follows:

1. Variant 1 [GenBank NM 024302]: 5'-CTGCGGCAGTGTCATTGAATG-3' (forward), 5'-GGGCCCCGGAACCT-3' (reverse), and 5'-CATCGACCCCCTTTGAAG-3' (probe).

2. Variant 2 [GenBank NM 032950]: 5'-CTGCGGCAGTGTCATTGAATG-3' (forward), 5'-CCCACGATGGTTGGTATTCATATCA-3' (reverse), and 5'TTCTTCAAAGTGCAATCCGT-3' (probe).

Relative quantification of genes was performed using the $A B I$ Prism 7700 sequence detection system (Applied Biosystems,
Warrington, UK) in accordance with the manufacturer's protocol. PCR reactions contained $5 \mathrm{ng}$ of reverse-transcribed RNA (1 ng for $18 S$ analyses), 50\% TaqMan 2X Master Mix (Applied Biosystems, Warrington, UK), $100 \mathrm{nM}$ of each primer and 200 $\mathrm{nM}$ of probe in a total volume of $25 \mu \mathrm{l}$. Conditions for the PCR reaction were as follows: 2 minutes at $50^{\circ} \mathrm{C}, 10$ minutes at $95^{\circ} \mathrm{C}, 40$ cycles of 15 seconds at $95^{\circ} \mathrm{C}$, and 1 minute at $60^{\circ} \mathrm{C}$.

The threshold cycle $\left(\mathrm{C}_{\mathrm{T}}\right)$, the cycle number at which signal is detectable above the baseline, was transformed in two ways. To gain an approximate comparison across all genes measured, amplification efficiency was assumed identical across all primer sets and target gene expression was normalized to $18 \mathrm{~S}$ expression using a logarithmic transformation proportional to normalized copy number $\left(\log _{10} 2^{-\Delta C T}\right)$, where $\Delta \mathrm{C}_{\mathrm{T}}$ is $\mathrm{C}_{\mathrm{T}}$ (target gene) $-\mathrm{C}_{\mathrm{T}}$ (18S) [30]. When comparing the expression of a single gene across the sample groups, standard curves for each gene were generated using the cDNA from one sample and making twofold serial dilutions across an appropriate range. Relative input amounts of template cDNA were then calculated from $\mathrm{C}_{\mathrm{T}}$ using the standard curves; data are pre- 


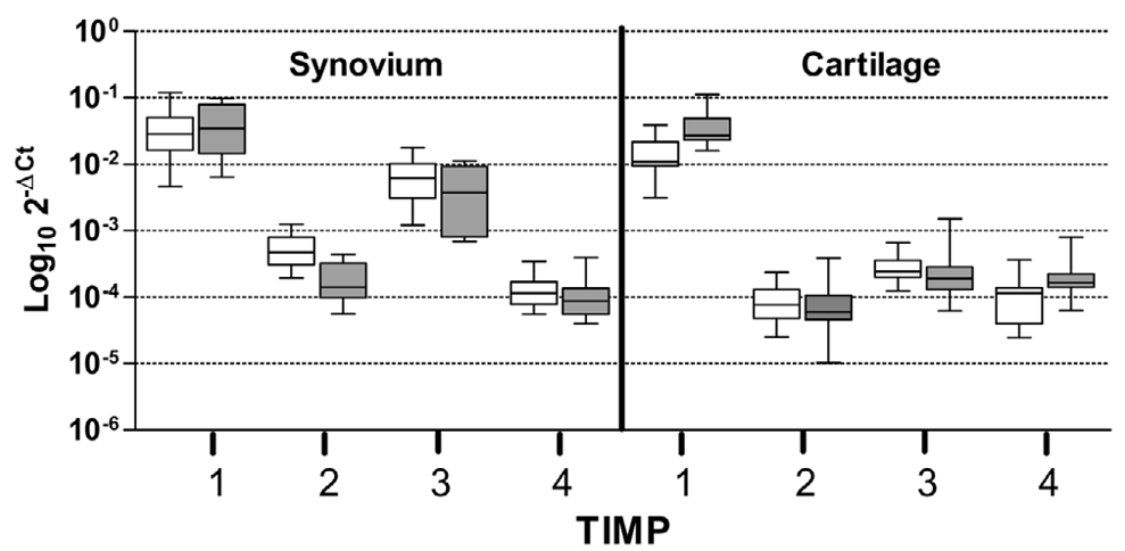

Comparative expression of TIMP genes in the fractured NOF (filled boxes) compared with OA (open boxes) hip synovium and cartilage. The expression level of each gene was determined, as described in Materials and methods, and normalized to the level of 18S rRNA gene expression using $\Delta \mathrm{C}_{\mathrm{T}}\left[\mathrm{C}_{\mathrm{T}}\right.$ (target gene) $\left.-\mathrm{C}_{\mathrm{T}}(18 \mathrm{~S})\right]$. The box-and-whisker plot shows median values, and each section represents a quartile of the data.

sented as relative levels of mRNA normalized to $18 \mathrm{~S}$ rRNA. Statistical analyses between OA and fractured NOF samples were performed using this latter method.

For comparison of expression levels between genes, cDNA for 18S, MMP13, MMP28 and ADAMTS16 was subcloned into a plasmid vector. Serial dilutions of these plasmids, between $10^{-12}$ moles and $10^{-23}$ moles DNA, were used to create a standard curve. This enabled $\mathrm{C}_{\mathrm{T}}$ to be converted into the number of cDNA molecules and calculation of the ratio of target gene to $18 \mathrm{~S}$.

As a final quality control for the purified RNA samples, only cDNA falling within $\pm 1.5 \mathrm{C}_{\mathrm{T}}$ of the median value for $18 \mathrm{~S}$ for all samples were used in the downstream study. To ascertain whether the amplification product was indeed that of the desired target gene, products were subcloned and sequenced. All primer and probe sets were shown to amplify specific products from appropriate human tissue samples $[28,29]$.

\section{Statistical analysis}

Differences between control and OA groups were defined using a two-sided Mann-Whitney $U$ test; this nonparametric test makes no prior assumption about the distribution of the data. Correlations between genes were assessed using Spearman's rank correlation.

\section{Results}

\section{Expression of the MMP gene family}

All MMP genes, with the exception of MMP20 (which we have previously shown to be expressed neither in cartilage nor in many other tissues), were profiled in synovium and cartilage tissues. OA cartilage was compared with tissue from fractured NOF, with results shown in Figure 1. MMP9 $(P<0.0001$ and $P=0.0204), M M P 11(P<0.0001$ and $P=0.0068), M M P 13$
$(P<0.0001$ and $P=0.0037), M M P 16(P=0.0014$ and $P=$ $0.036)$ and MMP28 $(P=0.0048$ and $P<0.0001)$ were all upregulated in $\mathrm{OA}$, both in cartilage and in synovium ( $P$ values represent cartilage and synovium, respectively). MMP10 $(P<$ 0.0001 and $P<0.0001$ ) was downregulated in both tissues ( $P$ values represent cartilage and synovium, respectively). MMP2 $(P<0.0001)$, MMP8 $(P=0.0135), M M P 15(P=$ 0.003), MMP17 $(P=0.0146), M M P 19(P<0.0001)$, MMP21 $(P=0.0007)$, MMP23 $(P<0.0001)$ and MMP24 $(P$ $=0.0212$ ) were upregulated in OA cartilage, but no significant change was seen in OA synovium. However, a trend towards an increase of MMP24 $(P=0.0536)$ in OA synovium was observed but did not reach statistical significance. MMP1 $(P$ $=0.0001), \operatorname{MMP3}(P<0.0001)$ and MMP12 $(P=0.0146)$ were downregulated in OA cartilage, but no significant change was observed in OA synovium. MMP25 and MMP26 were not detected in cartilage.

\section{Expression of the ADAMTS gene family}

All ADAMTS genes were profiled in synovium and cartilage tissues with $\mathrm{OA}$ and compared with tissue from fractured NOF (Figure 2). In both cartilage and synovium tissues, ADAMTS2 $(P<0.0001$ and $P=0.009), A D A M T S 10(P=0.048$ and $P$ $=0.02)$ and $A D A M T S 16(P<0.0001$ and $P<0.0001)$ were upregulated, whereas ADAMTS1 $(P=0.0011$ and $P=$ $0.0143)$, ADAMTS4 $(P=0.0043$ and $P<0.0001)$, ADAMTS5 $(P=0.0135$ and $P=0.0109)$ and ADAMTS9 $(P$ $<0.0001$ and $P<0.0001)$ were downregulated compared with the NOF samples. In OA cartilage, ADAMTS3 $(P=$ $0.0017)$, ADAMTS7 $(P=0.0002)$, ADAMTS12 $(P<0.0001)$, ADAMTS14 $(P<0.0001)$, ADAMTS15 $(P=0.045)$, ADAMTS18 $(P=0.0033)$ and ADAMTS20 $(P=0.0014)$, were upregulated, but no significant change was seen in synovium. In OA synovium, ADAMTS8 $(P=0.0017)$, ADAMTS13 $(P=0.0045)$ and $A D A M T S 17(P<0.0001)$ were upregulated, but no significant change was seen in cartilage. 
ADAMTS8 was not detected in cartilage tissue and no significant change in expression was seen in ADAMTS6 or ADAMTS19 genes in either cartilage or synovium.

\section{Expression of the TIMP gene family}

All TIMP genes were profiled in synovium and cartilage tissues with OA and compared with tissue from fractured NOF (Figure 3). In OA cartilage, TIMP1 $(P<0.0001)$ and TIMP4 $(P=$ $0.0033)$ were downregulated. No change was seen in TIMP2 or TIMP3 levels. In OA synovium, TIMP2 $(P<0.0001)$ was upregulated, but no significant changes were seen in TIMP1, TIMP3 or TIMP4 levels.

\section{Correlation of gene expression between tissues}

For $11 \mathrm{OA}$ and 13 NOF samples, cartilage and synovium taken from the same joint was analysed. Although these sample numbers are small for correlation analysis, a number of genes show a correlation in expression between tissues: MMP9 ( $r=0.584 ; P<0.01), M M P 10(r=0.645 ; P<0.001)$, MMP12 ( $r=-0.439 ; P<0.05), M M P 17(r=0.418 ; P<0.05)$, MMP23 $(r=0.411 ; P<0.05), M M P 28(r=0.412 ; P<0.05)$, ADAMTS4 $(r=0.521 ; P<0.01)$, ADAMTS9 $(r=0.611 ; P<$ $0.002)$, and ADAMTS16 ( $r=0.398 ; P=0.054)$. Figure 4 shows the two most significant correlations.

\section{Comparison of MMP13, MMP28 and ADAMTS16 expression}

In our previous work [26], the identification of MMP28 and ADAMTS16 as genes significantly upregulated in OA cartilage raised the question of how their expression levels compared with that of MMP13, the MMP pathognomic of collagen destruction in OA. Hence, we subcloned cDNA for each gene and used these to establish a standard curve of the absolute number of molecules of cDNA against the $\mathrm{C}_{\mathrm{T}}$ value. Figure 5 shows that the median level of expression of MMP13 is approximately 20 -fold higher than that of MMP28 in cartilage and approximately 1,500-fold higher than ADAMTS16. The median level of MMP13 is similar in cartilage and synovium, whereas MMP28 is expressed at an approximately eightfold higher level and ADAMTS16 is expressed at an approximately 150 -fold higher level in synovium compared with cartilage (data not shown).

\section{Expression of MMP28 splice variants}

Two splice variants of MMP28 are listed on the database [GenBank NM 024302 and NM 032950]. The longer mRNA includes exon 8, which contains an in-frame stop codon, leading to a protein truncated in the $\mathrm{C}$-terminal hemopexin-like domain; the shorter mRNA excludes exon 8 and encodes a protein with a complete C-terminal domain. Taqman primer/ probe sets were designed to distinguish between these variants and verify them against cloned cDNA. This demonstrated that only the shorter mRNA (encoding the full-length protein) was expressed at a detectable level in cartilage (data not shown).

\section{Discussion}

This is the first study to profile the expression of all MMP, ADAMTS and TIMP genes in synovium and compare tissue from OA patients with those who have a fracture to the NOF. Konttinen et al. had previously used conventional reverse-transcriptase PCR to profile the expression of 16 MMPs in synovium (MMP1-3, MMP7-17 and MMP19), with induction of MMP1, MMP9, MMP13, MMP14 and MMP15 in synovium from rheumatoid arthritis compared with trauma controls [31].

Recent studies show that inflammatory changes in the OA synovium are variable throughout the tissue $[23,24]$. This might be expected to confound measurement of regulated gene expression in this tissue because variation across the tissue within a single joint would lead to greater variation in gene expression within each patient group. This is borne out by our study, in which more genes showed significant regulation between OA and fractured NOF in cartilage than synovium.

Several studies have measured MMPs in synovium or synovial fluid and demonstrated that levels of MMP-1 and MMP-3 are elevated in rheumatoid arthritis (compared with $\mathrm{OA}$ or other control groups, such as joint trauma; e.g. [32-36]). High expression of a number of MMPs has been demonstrated in rheumatoid pannus, suggesting a role mediating cartilage destruction in RA (e.g. [31,37]). Indeed, levels of synovial fluid MMP-1 and MMP-3 correlate to synovial hyperplasia [38]. Although levels of synovial fluid MMPs are generally raised in RA compared with OA, the levels of at least MMP-1-3, MMP8, MMP-9 and TIMP-1 are reported to be raised in OA compared with control, nonarthritic, synovial fluid (e.g. $[39,40]$ ).

In this study, the four most significantly upregulated genes $(P$ $<0.0001$ ) in OA synovium compared with fracture of the NOF are MMP28, ADAMTS16, ADAMTS17 and TIMP2. Interestingly, we recently published the first report of MMP28 and ADAMTS16 gene expression in cartilage and their upregulation in OA [26]. Although these enzymes have no known function, the fact that their expression is switched on in at least two tissues of the OA joint underlines their probable role in this disease. ADAMTS17 is another recently cloned ADAMTS family member with unknown function and this is the first report of its expression in synovium. TIMP-2 can inhibit the activity of all the MMPs and the increase in expression in OA synovium might represent an attempt to control proteolysis. The expression of $M M P 13$, the probable key collagenase in OA, is also upregulated in OA synovium, in addition to cartilage.

MMP-1, MMP-2, MMP-9-11, MMP-13 and TIMP-2 are all expressed in human growth plate hypertrophic chondrocytes [41]. Interestingly, a significant subset of these (MMP2, MMP9, MMP11, MMP13 and TIMP2) is upregulated in OA cartilage. 
Figure 4
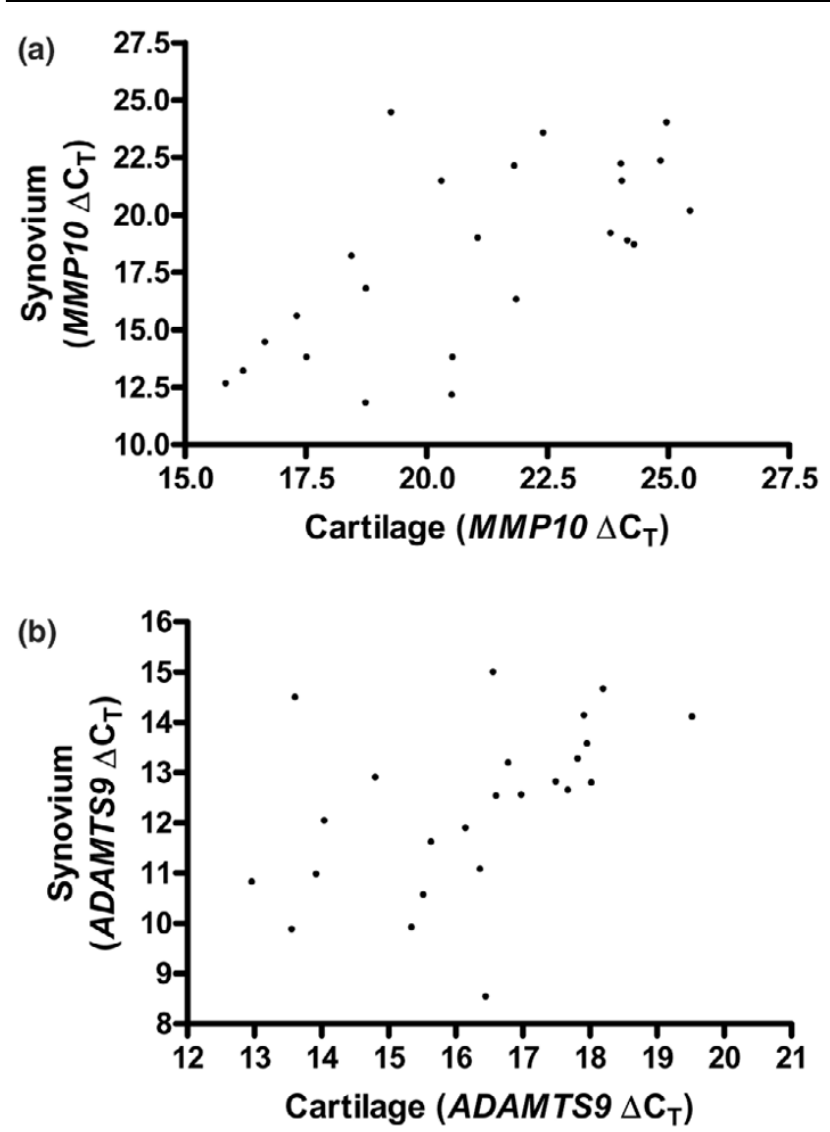

Correlation analysis of gene expression in cartilage compared with synovium. Correlation plots for (a) MMP10 and (b) ADAMTS9 expression in cartilage and synovium taken from the same joint. Correlation coefficients are as follows: MMP10, $r=0.645(P=0.0006)$; and ADAMTS9, $\mathrm{r}=0.590(P=0.0024)$.

MMP-1 and MMP-3 are the most frequently measured enzymes in RA, where correlations of synovial fluid or serum levels to disease activity have been reported $[36,39]$. Our data show that in synovium there is no difference in expression between OA and fracture to the NOF, whereas in cartilage, as we and others have previously reported, there is a significant downregulation of expression in OA $[26,42]$. This might reflect the late stage of the disease tissue in our study (see below), or, for MMP-3, a maintenance role in cartilage metabolism. Our data support the fact that MMP3 is a highly expressed gene in synovium, as previously reported [37].

Other genes expressed at significantly higher levels in OA synovium compared with fracture to the NOF are MMP9, MMP11, MMP16, ADAMTS8, ADAMTS10 and ADAMTS13, although the absolute expression of ADAMTS8 is low. MMP-9 has previously been reported as elevated in RA synovium (e.g. $[31,38])$ and in synovium and synovial fluid in a dog model of OA [43]. Elevated MMP11 expression has also been previously reported in late-stage OA [42]. MMP16 expression has
Figure 5

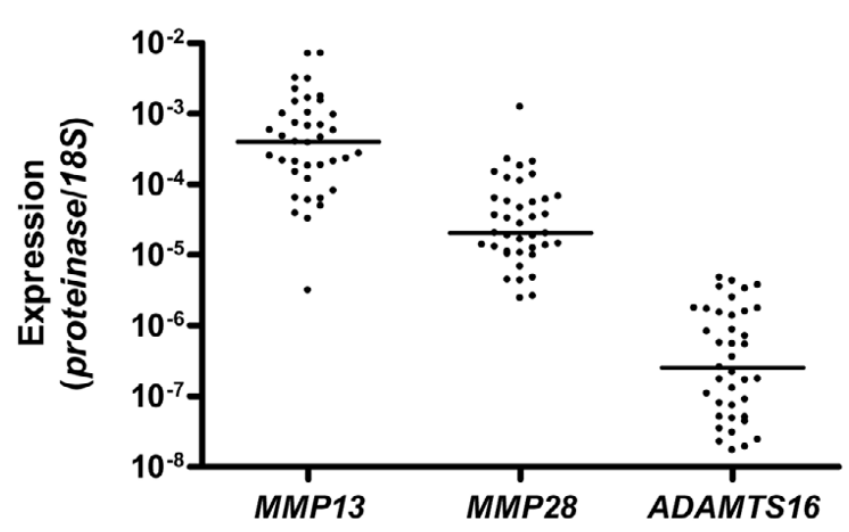

Comparison of MMP13, MMP28 and ADAMTS16 expression levels in cartilage. Expression of each gene was quantified against standard curves constructed using purified cDNA and normalized to $18 \mathrm{~S}$ expression, which was similarly quantified. Median values are marked.

been reported in synovium, but was not associated with disease [31], whereas ADAMTS8, ADAMTS10 and ADAMTS13 have not previously been described in synovium. ADAMTS-8 is capable of degrading aggrecan [44], although with lesser catalytic efficiency compared with, for example, ADAMTS-4 or ADAMTS-5.

The expression of MMP10 was the most significantly downregulated of any $M M P$ in OA synovium compared with fractured NOF. MMP10 expression has been previously described in synovium, but its regulation has not been described in disease [31]. MMP10 expression has also been associated with the invasive potential of synovial fibroblasts in both OA and RA [45].

We previously reported that the expression of ADAMTS4, ADAMTS5 and ADAMTS9, all aggrecanases, was downregulated in OA cartilage compared with fractured NOF [26]. These genes, particularly ADAMTS4 and ADAMTS9, are also downregulated in OA synovium. This could reflect a role for aggrecanases in the earlier phases of OA, but similar expression patterns in cartilage and synovium could also suggest a role for the synovium in aggrecan turnover and breakdown. Synovium has been shown to express soluble aggrecanase activity [46], and ADAMTS-5 has been localized to human synovium [47].

A comparison of the expression patterns of MMP, ADAMTS and TIMP genes in cartilage in this study with those in our previous report shows predominantly similar data. Overall, a greater number of genes were regulated between $\mathrm{OA}$ and fractured NOF samples in the current study. This might reflect differences in the actual patient groups in each study or the rapidity of tissue dissection and processing. Genes induced in OA with weak significance in the current study, MMP17, 
Table 1

Genes with changing expression levels in cartilage or synovium when comparing OA with fracture to the NOF

\begin{tabular}{|c|c|c|c|c|}
\hline \multirow[t]{2}{*}{$P$ value } & \multicolumn{2}{|c|}{ Cartilage } & \multicolumn{2}{|c|}{ Synovium } \\
\hline & Up & Down & Up & Down \\
\hline \multirow[t]{5}{*}{$<0.05$} & MMP8 & ADAMTS5 & MMP9 & ADAMTS1 \\
\hline & MMP17 & & MMP16 & ADAMTS5 \\
\hline & MMP24 & & ADAMTS10 & \\
\hline & ADAMTS10 & & & \\
\hline & ADAMTS15 & & & \\
\hline \multirow[t]{6}{*}{$<0.01$} & MMP15 & MMP12 & MMP11 & \\
\hline & MMP16 & ADAMTS1 & MMP13 & \\
\hline & MMP28 & ADAMTS4 & ADAMTS2 & \\
\hline & ADAMTS3 & TIMP4 & ADAMTS8 & \\
\hline & ADAMTS18 & & ADAMTS13 & \\
\hline & ADAMTS20 & & & \\
\hline \multirow[t]{2}{*}{$<0.001$} & MMP21 & & & \\
\hline & ADAMTS7 & & & \\
\hline \multirow[t]{10}{*}{$<0.0001$} & MMP2 & $M M P 1$ & MMP28 & MMP10 \\
\hline & MMP9 & $M M P 3$ & ADAMTS16 & ADAMTS4 \\
\hline & MMP11 & MMP10 & ADAMTS17 & ADAMTS9 \\
\hline & MMP13 & ADAMTS9 & TIMP2 & \\
\hline & MMP19 & TIMP1 & & \\
\hline & MMP23 & & & \\
\hline & ADAMTS2 & & & \\
\hline & ADAMTS12 & & & \\
\hline & ADAMTS14 & & & \\
\hline & ADAMTS16 & & & \\
\hline
\end{tabular}

MMP24 and ADAMTS10, all show a trend towards induction in our previous cohort but did not reach significance. The same is true for MMP12, MMP15 and ADAMTS3. ADAMTS15 showed upregulation in OA in the current study at $P<0.05$ and similarly significant downregulation in our previous study. This might represent variation because of multiple testing. More difficult to explain are the significantly upregulated genes in OA in the current study, MMP21 $(P<0.001)$, MMP19 $(P<0.0001)$ and MMP23 $(P<0.0001)$; these genes showed no significant difference in our earlier cohort. Where genes are annotated as 'not detected' (Figures 1, 2, 3 and [26], these might not be expressed at all in the tissue or the median $C_{T}$ is 40 , with a few samples showing a low level of

expression.
For MMP9, MMP10, MMP12, MMP17, MMP23, MMP28, ADAMTS4, and ADAMTS9, there is a significant correlation between expression levels in the synovium and cartilage. This presumably reflects the fact that these tissues are exposed to a similar environment in terms of growth factors and cytokines. For genes where expression between the two tissues does not correlate, there must therefore be other factors driving expression, such as mechanical load, oxidative stress and cell-matrix interaction.

To resolve previously raised questions, we used plasmid cDNA for MMP13, MMP28 and ADAMTS16 to construct standard curves for these genes. This demonstrated that MMP13 was the most abundant mRNA of the three genes. It remains impossible to speculate about their relative impor- 
tance because the substrates, and therefore the specific activities of MMP-28 and ADAMTS-16, are unknown.

\section{Conclusion}

This study is the most comprehensive analysis of the metzincin family of proteinases in the joint to date and has identified several proteinase genes not previously reported to be expressed or regulated in synovium. Future work will focus on the function of key genes. The data also show coordinate regulation of a subset of genes throughout the synovium and cartilage that might inform analyses of regulatory pathways and transcription factors.

\section{Competing interests}

The authors declare that they have no competing interests.

\section{Authors' contributions}

RKD helped design and coordinate the study, collected and processed tissue samples, performed real-time PCR, analysed data and helped draft the manuscript; JGW and LK helped in collecting and processing tissue samples; CD and $A C$ took patient consent and coordinated tissue collection; STD helped design and coordinate study, tissue collection and interpretation of data; IMC helped conceive, design and coordinate the study, and helped to draft the manuscript. All authors read and approved the final manuscript.

\section{Acknowledgements}

This work was supported by a PhD studentship to RKD from the Arthritis Research Campaign UK. JGW was supported by the Action Arthritis Trust. We are also indebted to Dylan Edwards, Caroline Pennington and Rob Nutall for advice on real-time PCR.

\section{References}

1. The Arthritis Research Campaign, UK [http://www.arc.org.uk/ about arth/bigpic.htm]

2. Wieland HA, Michaelis M, Kirschbaum BJ, Rudolphi KA: Osteoarthritis - an untreatable disease? Nat Rev Drug Discov 2005, 4:331-344

3. Roughley PJ: Articular cartilage and changes in arthritis: noncollagenous proteins and proteoglycans in the extracellular matrix of cartilage. Arthritis Res 2001, 3:342-347.

4. Eyre D: Collagen of articular cartilage. Arthritis Res 2002, 4:30-35.

5. Murphy G, Knauper V, Atkinson S, Butler G, English W, Hutton M, Stracke J, Clark I: Matrix metalloproteinases in arthritic disease. Arthritis Res 2002, 4(Suppl 3):S39-49.

6. Knauper V, Lopez-Otin C, Smith B, Knight G, Murphy G: Biochemical characterization of human collagenase-3. J Biol Chem 1996, 271:1544-1550.

7. d'Ortho MP, Will H, Atkinson S, Butler G, Messent A, Gavrilovic J, Smith B, Timpl R, Zardi L, Murphy G: Membrane-type matrix metalloproteinases 1 and 2 exhibit broad-spectrum proteolytic capacities comparable to many matrix metalloproteinases. Eur J Biochem 1997, 250:751-757.

8. Ohuchi E, Imai K, Fujii Y, Sato H, Seiki M, Okada Y: Membrane type 1 matrix metalloproteinase digests interstitial collagens and other extracellular matrix macromolecules. J Biol Chem 1997, 272:2446-2451.

9. Porter S, Clark IM, Kevorkian L, Edwards DR: The ADAMTS metalloproteinases. Biochem J 2005, 386:15-27.

10. Li SW, Arita M, Fertala A, Bao Y, Kopen GC, Langsjo TK, Hyttinen MM, Helminen HJ, Prockop DJ: Transgenic mice with inactive alleles for procollagen N-proteinase (ADAMTS-2) develop fragile skin and male sterility. Biochem J 2001, 355:271-278.

11. Fernandes RJ, Hirohata S, Engle JM, Colige A, Cohn DH, Eyre DR, Apte SS: Procollagen II amino propeptide processing by ADAMTS-3. Insights on dermatosparaxis. J Biol Chem 2001, 276:31502-31509.

12. Bolz $\mathrm{H}$, Ramirez $\mathrm{A}$, von Brederlow $B$, Kubisch $\mathrm{C}$ : Characterization of ADAMTS14, a novel member of the ADAMTS metalloproteinase family. Biochim Biophys Acta 2001, 1522:221-225.

13. Colige A, Vandenberghe I, Thiry M, Lambert CA, Van Beeumen J, Li SW, Prockop DJ, Lapiere CM, Nusgens BV: Cloning and characterization of ADAMTS-14, a novel ADAMTS displaying high homology with ADAMTS-2 and ADAMTS-3. J Biol Chem 2002, 277:5756-5766.

14. Somerville RP, Longpre JM, Jungers KA, Engle JM, Ross M, Evanko S, Wight TN, Leduc R, Apte SS: Characterization of ADAMTS-9 and ADAMTS-20 as a distinct ADAMTS subfamily related to Caenorhabditis elegans GON-1. J Biol Chem 2003, 278:9503-9513.

15. Tortorella MD, Burn TC, Pratta MA, Abbaszade I, Hollis JM, Liu R, Rosenfeld SA, Copeland RA, Decicco CP, Wynn R, et al:: Purification and cloning of aggrecanase-1: a member of the ADAMTS family of proteins. Science 1999, 284:1664-1666.

16. Kuno $\mathrm{K}$, Okada $\mathrm{Y}$, Kawashima $\mathrm{H}$, Nakamura $\mathrm{H}$, Miyasaka $\mathrm{M}$, Ohno $\mathrm{H}$, Matsushima $\mathrm{K}$ : ADAMTS-1 cleaves a cartilage proteoglycan, aggrecan. FEBS Lett 2000, 478:241-245.

17. Rodriguez-Manzaneque JC, Westling J, Thai SN, Luque A, Knauper V, Murphy G, Sandy JD, Iruela-Arispe ML: ADAMTS1 cleaves aggrecan at multiple sites and is differentially inhibited by metalloproteinase inhibitors. Biochem Biophys Res Commun 2002, 293:501-508.

18. Abbaszade I, Liu RQ, Yang F, Rosenfeld SA, Ross OH, Link JR, Ellis DM, Tortorella MD, Pratta MA, Hollis JM, et al.: Cloning and characterization of ADAMTS11, an aggrecanase from the ADAMTS family. J Biol Chem 1999, 274:23443-23450.

19. Baker $\mathrm{AH}$, Edwards DR, Murphy G: Metalloproteinase inhibitors: biological actions and therapeutic opportunities. I Cell Sci 2002, 115:3719-3727.

20. Kashiwagi M, Tortorella M, Nagase H, Brew K: TIMP-3 is a potent inhibitor of aggrecanase 1 (ADAM-TS4) and aggrecanase 2 (ADAM-TS5). J Biol Chem 2001, 276:12501-12504.

21. Smith MD, Triantafillou S, Parker A, Youssef PP, Coleman M: Synovial membrane inflammation and cytokine production in patients with early osteoarthritis. J Rheumatol 1997, 24:365-371.

22. Young L, Katrib A, Cuello C, Vollmer-Conna U, Bertouch JV, Roberts-Thomson PJ, Ahern MJ, Smith MD, Youssef PP: Effects of intraarticular glucocorticoids on macrophage infiltration and mediators of joint damage in osteoarthritis synovial membranes: findings in a double-blind, placebo-controlled study. Arthritis Rheum 2001, 44:343-350.

23. Lindblad S, Hedfors E: Arthroscopic and immunohistologic characterization of knee joint synovitis in osteoarthritis. Arthritis Rheum 1987, 30:1081-1088.

24. Ayral X, Dougados M, Listrat V, Bonvarlet JP, Simonnet J, Amor B: Arthroscopic evaluation of chondropathy in osteoarthritis of the knee. J Rheumatol 1996, 23:698-706.

25. Loeuille D, Chary-Valckenaere I, Champigneulle J, Rat AC, Toussaint F, Pinzano-Watrin A, Goebel JC, Mainard D, Blum A, Pourel $\mathrm{J}$, et al.: Macroscopic and microscopic features of synovial membrane inflammation in the osteoarthritic knee: correlating magnetic resonance imaging findings with disease severity. Arthritis Rheum 2005, 52:3492-3501.

26. Kevorkian L, Young DA, Darrah C, Donell ST, Shepstone L, Porter S, Brockbank SM, Edwards DR, Parker AE, Clark IM: Expression profiling of metalloproteinases and their inhibitors in cartilage. Arthritis Rheum 2004, 50:131-141.

27. Price JS, Waters JG, Darrah C, Pennington C, Edwards DR, Donell ST, Clark IM: The role of chondrocyte senescence in osteoarthritis. Aging Cell 2002, 1:57-65.

28. Nuttall RK, Pennington CJ, Taplin J, Wheal A, Yong VW, Forsyth PA, Edwards DR: Elevated membrane-type matrix metalloproteinases in gliomas revealed by profiling proteases and inhibitors in human cancer cells. Mol Cancer Res 2003, 1:333-345.

29. Porter S, Scott SD, Sassoon EM, Williams MR, Jones JL, Girling AC, Ball RY, Edwards DR: Dysregulated expression of adama- 
lysin-thrombospondin genes in human breast carcinoma. Clin Cancer Res 2004, 10:2429-2440.

30. Jones GC, Corps AN, Pennington CJ, Clark IM, Edwards DR, Bradley MM, Hazleman BL, Riley GP: Expression profiling of metalloproteinases and tissue inhibitors of metalloproteinases in normal and degenerate human achilles tendon. Arthritis Rheum 2006, 54:832-842.

31. Konttinen YT, Ainola M, Valleala $\mathrm{H}, \mathrm{Ma} J$, Ida $\mathrm{H}$, Mandelin J, Kinne RW, Santavirta S, Sorsa T, López-Otin C, Takagi M: Analysis of 16 different matrix metalloproteinases (MMP-1 to MMP-20) in the synovial membrane: different profiles in trauma and rheumatoid arthritis. Ann Rheum Dis 1999, 58:691-697.

32. Gravallese EM, Darling JM, Ladd AL, Katz JN, Glimcher LH: In situ hybridization studies of stromelysin and collagenase messenger RNA expression in rheumatoid synovium. Arthritis Rheum 1991, 34:1076-1084.

33. Clark IM, Powell LK, Ramsey S, Hazleman BL, Cawston TE: The measurement of collagenase, tissue inhibitor of metalloproteinases (TIMP), and collagenase-TIMP complex in synovial fluids from patients with osteoarthritis and rheumatoid arthritis. Arthritis Rheum 1993, 36:372-379.

34. Walakovits LA, Moore VL, Bhardwaj N, Gallick GS, Lark MW: Detection of stromelysin and collagenase in synovial fluid from patients with rheumatoid arthritis and posttraumatic knee injury. Arthritis Rheum 1992, 35:35-42.

35. Yoshihara $Y$, Nakamura $H$, Obata $K$, Yamada $H$, Hayakawa $T$, Fujikawa $\mathrm{K}$, Okada $\mathrm{Y}$ : Matrix metalloproteinases and tissue inhibitors of metalloproteinases in synovial fluids from patients with rheumatoid arthritis or osteoarthritis. Ann Rheum Dis 2000, 59:455-461.

36. Cunnane G, Fitzgerald O, Beeton C, Cawston TE, Bresnihan B: Early joint erosions and serum levels of matrix metalloproteinase 1, matrix metalloproteinase 3 , and tissue inhibitor of metalloproteinases 1 in rheumatoid arthritis. Arthritis Rheum 2001, 44:2263-2274.

37. Ainola MM, Mandelin JA, Liljestrom MP, Li TF, Hukkanen MV, Konttinen YT: Pannus invasion and cartilage degradation in rheumatoid arthritis: involvement of MMP-3 and interleukin-1 $\beta$. Clin Exp Rheumatol 2005, 23:644-650.

38. Fraser A, Fearon U, Billinghurst RC, lonescu M, Reece R, Barwick T, Emery P, Poole AR, Veale DJ: Turnover of type II collagen and aggrecan in cartilage matrix at the onset of inflammatory arthritis in humans: relationship to mediators of systemic and local inflammation. Arthritis Rheum 2003, 48:3085-3095.

39. Tchetverikov I, Ronday HK, Van El B, Kiers GH, Verzijl N, TeKoppele JM, Huizinga TW, DeGroot J, Hanemaaijer R: MMP profile in paired serum and synovial fluid samples of patients with rheumatoid arthritis. Ann Rheum Dis 2004, 63:881-883.

40. Tchetverikov I, Lohmander LS, Verzijl N, Huizinga TW, TeKoppele JM, Hanemaaijer R, DeGroot J: MMP protein and activity levels in synovial fluid from patients with joint injury, inflammatory arthritis, and osteoarthritis. Ann Rheum Dis 2005, 64:694-698.

41. Haeusler G, Walter I, Helmreich M, Egerbacher M: Localization of matrix metalloproteinases, (MMPs) their tissue inhibitors, and vascular endothelial growth factor (VEGF) in growth plates of children and adolescents indicates a role for MMPs in human postnatal growth and skeletal maturation. Calcif Tissue Int 2005, 76:326-335.

42. Aigner T, Zien A, Gehrsitz A, Gebhard PM, McKenna L: Anabolic and catabolic gene expression pattern analysis in normal versus osteoarthritic cartilage using complementary DNA-array technology. Arthritis Rheum 2001, 44:2777-2789.

43. Volk SW, Kapatkin AS, Haskins ME, Walton RM, D'Angelo M: Gelatinase activity in synovial fluid and synovium obtained from healthy and osteoarthritic joints of dogs. Am J Vet Res 2003, 64:1225-1233.

44. Collins-Racie LA, Flannery CR, Zeng W, Corcoran C, Annis-Freeman B, Agostino MJ, Arai M, DiBlasio-Smith E, Dorner AJ, Georgiadis KE, et al.: ADAMTS- 8 exhibits aggrecanase activity and is expressed in human articular cartilage. Matrix Biol 2004, 23:219-230.

45. Tolboom TC, Pieterman E, van der Laan WH, Toes RE, Huidekoper AL, Nelissen RG, Breedveld FC, Huizinga TW: Invasive properties of fibroblast-like synoviocytes: correlation with growth characteristics and expression of MMP-1, MMP-3, and MMP10. Ann Rheum Dis 2002, 61:975-980.
46. Vankemmelbeke MN, llic MZ, Handley CJ, Knight CG, Buttle DJ: Coincubation of bovine synovial or capsular tissue with cartilage generates a soluble "Aggrecanase" activity. Biochem Biophys Res Commun 1999, 255:686-691.

47. Vankemmelbeke MN, Holen I, Wilson AG, Ilic MZ, Handley CJ, Kelner GS, Clark M, Liu C, Maki RA, Burnett D, Buttle DJ: Expression and activity of ADAMTS-5 in synovium. Eur J Biochem 2001, 268:1259-1268. 